\title{
ILHAS DE CALOR EM BIRIGUI/SP
}

\section{Margarete Cristiane de Costa Trindade Amorim ${ }^{1}$}

\begin{abstract}
RESUMO
A pesquisa teve como objetivo analisar a intensidade da ilha de calor em Birigui/SP. A cidade localiza-se à $21^{\circ} 16^{\prime} 53^{\prime \prime}$ de latitude Sul e $50^{\circ} 19^{\prime} 35^{\prime \prime}$ de longitude Oeste, no estado de São Paulo - Brasil, e possui população aproximada de 94.300 habitantes. A metodologia para a coleta de temperatura consistiu na definição de um transecto, com medidas móveis, utilizando-se de termômetros digitais, com os sensores presos a uma haste de madeira com $1,5 \mathrm{~m}$ de comprimento, acoplados na lateral de um veículo, totalizando 56 pontos de coletas de temperatura do ar. As medições foram efetuadas em dezembro de 2004 e janeiro de 2005, entre 20:00h e 20:45h, por 8 dias representativos do verão - quente e chuvoso. Esta pesquisa concluiu que Birigui apresenta características de um clima específico e durante os dias representativos de verão ficou comprovada a formação de ilhas de calor e de frescor. Os resultados possibilitaram identificar ilhas de calor com intensidade máxima de $6.2^{\circ} \mathrm{C}$. As variações espaciais ocorreram de acordo com os tipos de ocupação do solo e características de relevo.
\end{abstract}

Palavras chave: clima urbano, ilhas de calor, medições móveis, Birigui.

HEAT ISLANDS IN BIRIGUI-SP, BRAZIL

\begin{abstract}
The goal of this research was to analyze the intensity of the urban heat island in Birigui/SP. The city is located at $21^{\circ} 16^{\prime} 53^{\prime \prime} \mathrm{S}$ and $50^{\circ} 19^{\prime} 35^{\prime \prime} \mathrm{W}$, in the State of São Paulo, Brazil, with a population of about 94,300 inhabitants. The method to measure temperature consisted in defining one dynamic measurement transect using digital thermometer with sensor adjusted to a 1.5 meter long wooden rod, fitted to the sides of one vehicle, with a total of 56 locations for air temperature measurements. This measurements were carried out through December 2004 to January 2005, from $8.00 \mathrm{pm}$ to $8.45 \mathrm{pm}$, during eight days representing the hot and rainy summer. This study concluded that Birigui shows characteristics of a specific climate, and during the days representing the summer, the formation of heat and freshness islands was proved. Based on the findings, it was possible to identify heat islands with a maximum intensity of $6.2^{\circ} \mathrm{C}$. Spatial variations took place according to the land uses and the nature of the relief.
\end{abstract}

Keywords: urban climate, heat island, dynamic measurement, Birigui

1 Profa. Dra. do Curso de Graduação e de Pós-Graduação em Geografia da FCT - UNESP Presidente Prudente. Rua Roberto Simonsen, 305. CEP 19060-900. Presidente Prudente SP. mccta@prudente.unesp.br. 


\section{Introdução}

A cidade constitui a forma mais evidente de transformação da paisagem natural. A modificação nos elementos do clima possui grande repercussão ecológica, pelo fato de afetar de maneira imediata os habitantes através do desconforto térmico e da concentração de poluentes.

O fenômeno da ilha de calor urbana caracteriza-se pelo aumento da temperatura do ar nas cidades em relação ao meio rural e as áreas menos urbanizadas. Habitualmente, ocorrem no centro das cidades, onde as construções formam um conjunto denso e compacto.

O parâmetro mais importante que caracteriza a ilha de calor é sua intensidade ou magnitude, que geralmente evolui mediante a diferença máxima observada, em um momento determinado, entre a temperatura de um ponto da cidade, densamente construído, e outro em seu entorno ou no ambiente rural.

O presente estudo teve como objetivo analisar a intensidade da ilha de calor em Birigui no período noturno, em dias representativos do verão.

Birigui localiza-se a noroeste do estado de São Paulo, cerca de $521 \mathrm{Km}$ da capital paulista, a $21^{\circ} 16^{\prime} 53^{\prime \prime}$ de latitude sul e $50^{\circ} 19^{\prime} 35^{\prime \prime}$ de longitude oeste. Pertence a 9a Região Administrativa (Região Administrativa de Araçatuba) com extensão territorial de aproximadamente $531 \mathrm{~km}^{2}$. Tem altitude média de 400 metros e faz parte do Planalto Ocidental Paulista, com modelado predominante de colinas amplas e baixas.

Possui 94.300 habitantes, sendo 91.018 concentrados na área urbana. A maioria da população economicamente ativa encontra-se respectivamente na atividade industrial, comercial e agropecuária. No início a cidade contava com um limitado parque industrial que apenas se encarregava de exercer o beneficiamento dos produtos agrícolas.

A partir de 1960 a indústria de Birigui apresentou crescimento significativo, principalmente no setor calçadista. Nos dias atuais, além do setor calçadista, há vários outros, tais como: o moveleiro, o metalúrgico, o cartonagem, o químico e o gráfico. Das aproximadamente 600 indústrias, 246 são do setor calçadista. Possui 1701 estabelecimentos comerciais e 1042 prestadores de serviços.

No setor agropecuário as pequenas propriedades rurais caracterizam-se pelo cultivo de hortaliças, cereais e pecuária leiteira. Nos latifúndios predomina a pecuária de corte e o cultivo em larga escala de milho, cana e soja que empregam número reduzido de trabalhadores buscando atender as demandas locais e regionais.

Birigui demonstra uma diversidade sócio-econômica que está evidenciada nas relações espaciais, sobretudo nas formas de uso e ocupação do solo.

Conforme caracteriza Castilho (2005), o município de Birigui apresenta 136 bairros, sendo estes ocupados em sua maioria por residências de alvenaria. Em alguns destes bairros existem construções de médio e grande porte como fábricas, galpões e armazéns.

$\mathrm{Na}$ área central concentram-se edificações que variam de dois a dez pavimentos, os estabelecimentos comerciais (edificações antigas) e algumas praças públicas que apresentam em sua constituição vegetação arbórea de médio e pequeno porte. Esta área demonstra alto grau de impermeabilização 
identificado por meio da pavimentação e da ocupação por construções de alvenaria.

No entorno da área central predominam os bairros mais antigos caracterizados como residenciais. Nesses bairros há maior quantidade de vegetação arbórea nas ruas e fundos de quintais.

A área periférica da cidade devido aos planos habitacionais (CDHU) e loteamentos autorizados pela Prefeitura Municipal, apresenta esparsa vegetação, grande quantidade de terrenos com gramíneas e pouca impermeabilização, pois inexiste pavimentação asfáltica.

Birigui possui um recente Distrito Industrial em que predominam muitos terrenos com gramíneas, áreas com pouca vegetação arbórea e ruas impermeabilizadas.

Todo o sítio urbano está caracterizado pela existência de poucas áreas verdes e de lazer, sendo em sua maioria praças públicas de pequeno porte e campos abertos com gramíneas.

Nos condomínios fechados existe maior preocupação com a qualidade ambiental, pois apresentam considerável quantidade de vegetação arbórea, pouca impermeabilização e áreas de lazer.

A área rural próxima caracteriza-se por pastagens e áreas agricultáveis com o cultivo de soja, milho e principalmente cana, apresentando pouca vegetação original e alguns recursos hídricos em processo de assoreamento devido a retirada de grande parte da mata ciliar.

\section{Procedimentos metodológicos}

A metodologia para a coleta de temperatura utilizada neste trabalho consistiu na definição de transecto, com medidas móveis, utilizando-se de termômetro digital, com o sensor preso a uma haste de madeira com 1,5m de comprimento, acoplado na lateral de um veículo que saiu da periferia (rural), passou pelo centro e chegou no extremo oposto da cidade. A cidade não dispõe de estação meteorológica para que se realizasse uma análise das características do clima em uma série histórica.

A coleta de dados com veículo requer que o tempo gasto entre a medida do ponto inicial e no ponto final do itinerário não ultrapasse uma hora, com velocidade que deve variar entre 30 e $40 \mathrm{Km} / \mathrm{h}$. Esta metodologia foi adaptada, com base nos trabalhos de Oke e Maxwell (1975); Gomez e Garcia (1984); Johnson (1985); Pitton (1997).

As medições foram efetuadas em 8 dias entre 24 de dezembro de 2004 e $1^{\circ}$ de janeiro de 2005, a partir das 20:00h, horário que as temperaturas não experimentam mudanças rápidas, justamente pela diferença de tempo entre a primeira e a última medida. O percurso realizado em Birigui durou cerca de 35 minutos e foram realizados 56 registros.

Os sistemas atmosféricos regionais que atuaram nos dias de levantamento de campo foram analisados através de cartas sinóticas de superfície disponibilizadas no sítio da Marinha do Brasil $^{2}$ e das imagens de satélite $\mathrm{GOES}^{3}$.

\footnotetext{
2 http://www.mar.mil.br

3 http://satelite.cptec.inpe.br/imagens
} 
Para a análise dos resultados foram elaboradas cartas de isotermas, através do Software Surfer for Windows, permitindo assim a visualização da variação da temperatura nos diferentes pontos das cidades.

\subsection{Intensidade das ilhas de calor em Birigui}

Nos oito dias em que foram realizadas as leituras da temperatura em Birigui, cinco deles (24, 28, 29, 30 e 31/12/2004) apresentaram condições sinóticas favoráveis à manifestação do fenômeno ilha de calor de forte magnitude, com baixa velocidade do vento e nebulosidade quase inexistente.

Nos dias que antecederam a realização da coleta da temperatura, entre 21/12/2004 e 23/12/2004, observou-se aumento de nebulosidade, com ocorrência de chuvas isoladas e conseqüente elevação de umidade ocasionada principalmente pela atuação de zonas de instabilidade (ZCAS) que se mantiveram alinhadas com uma frente fria no litoral da Região Sudeste.

No dia 24/12/2004, sob atuação da Massa Tropical Continental (TC) no Estado de São Paulo, as temperaturas apresentaram-se elevadas e a nebulosidade reduzida. Em Birigui havia vento fraco, que foi classificado segundo a "Escala de Força de Vento de Beaufort" entre 0 e 0,5m/seg., e o céu apresentava pouquíssimas nuvens. A amplitude térmica entre os pontos foi de $4,4^{\circ} \mathrm{C}$. (Figura 1 )

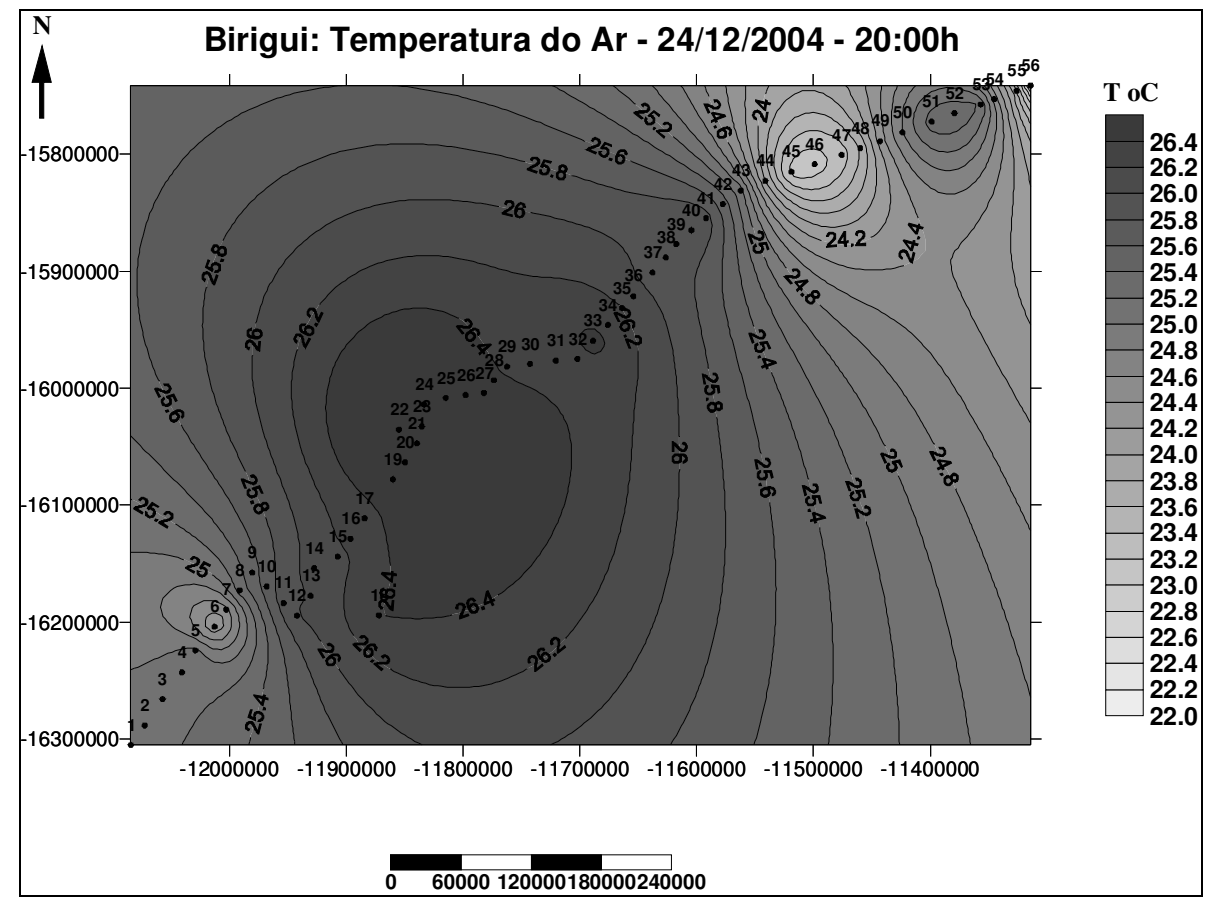

Figura 1. Carta de isotermas: Birigui - 24/12/2004 - 20:00 h.

A cidade apresentou ilhas de calor de forte magnitude, pois segundo Garcia (1996), pode-se classificar a ilha de calor de fraca magnitude, quando as diferenças entre os pontos oscilam entre $0{ }^{\circ} \mathrm{Ce} 2{ }^{\circ} \mathrm{C}$, média magnitude entre $2^{\circ} \mathrm{C}$ e $4{ }^{\circ} \mathrm{C}$, forte entre $4{ }^{\circ} \mathrm{C}$ e $6{ }^{\circ} \mathrm{C}$ e muito forte quando as diferenças forem superiores a $6{ }^{\circ} \mathrm{C}$. 
No dia 25/12/2004, predominou sobre o Sudeste Brasileiro uma área de convergência de umidade (ZCAS) que se mostrou alinhada com uma frente fria que atuou entre os estados do Rio de Janeiro e Espírito Santo. Esta área de convergência de umidade provocou precipitação de intensidade fraca sobre o município durante à tarde. Durante a noite o céu ficou cerca de $60 \%$ coberto por nuvens e a velocidade do vento entre 3,4 e $5,2 \mathrm{~m} / \mathrm{seg}$., segundo a escala de Beaufort.

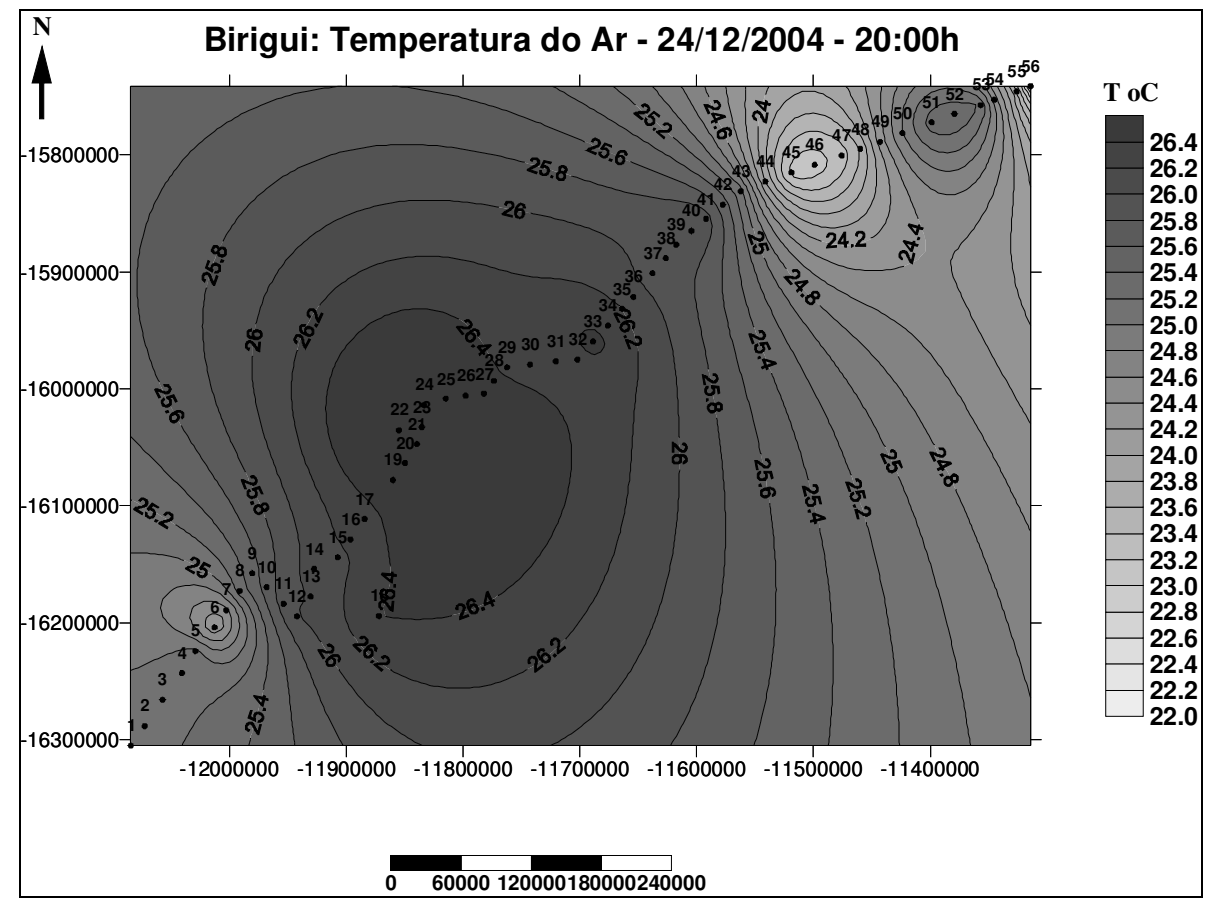

Figura 2. Carta de isotermas: Birigui - 25/12/2004 - 20:00 h.

Através da análise das isotermas no dia 25/12/2004 (Figura 2), observou-se que as diferenças da temperatura urbano-rural diminuíram em relação ao dia $24 / 12$, atingindo amplitude de $2,1^{\circ} \mathrm{C}$. Este fato foi conseqüência do aumento da velocidade do vento, que foi classificado entre 3,4 e 5,2m/seg.

No dia 26/12, verificou-se aumento de nebulosidade, fraca precipitação e conseqüente diminuição de temperatura. Esse comportamento foi ocasionado por uma Massa Polar que sustentava a atuação de uma frente fria no litoral do Sudeste Brasileiro associada a áreas de instabilidade. Devido a precipitação, não se realizou o levantamento da temperatura com o transecto neste dia.

No período de 27/12 a 29/12, ainda sob atuação da Massa Polar as temperaturas apresentaram-se em constante elevação e não houve precipitação. A nebulosidade foi variável devido a atuação de áreas de convergência de umidade (ZCAS) alinhadas com frentes frias que atuaram no litoral da Região Sudeste e Sul neste período.

No dia $27 / 12$ a amplitude térmica entre os pontos foi de $2,4^{\circ} \mathrm{C}$, a velocidade do vento oscilou entre $1,8-3,3 \mathrm{~m} / \mathrm{s}$ de nordeste, deslocando a ilha de calor de média magnitude para o sudoeste da malha urbana. (Figura 3). 


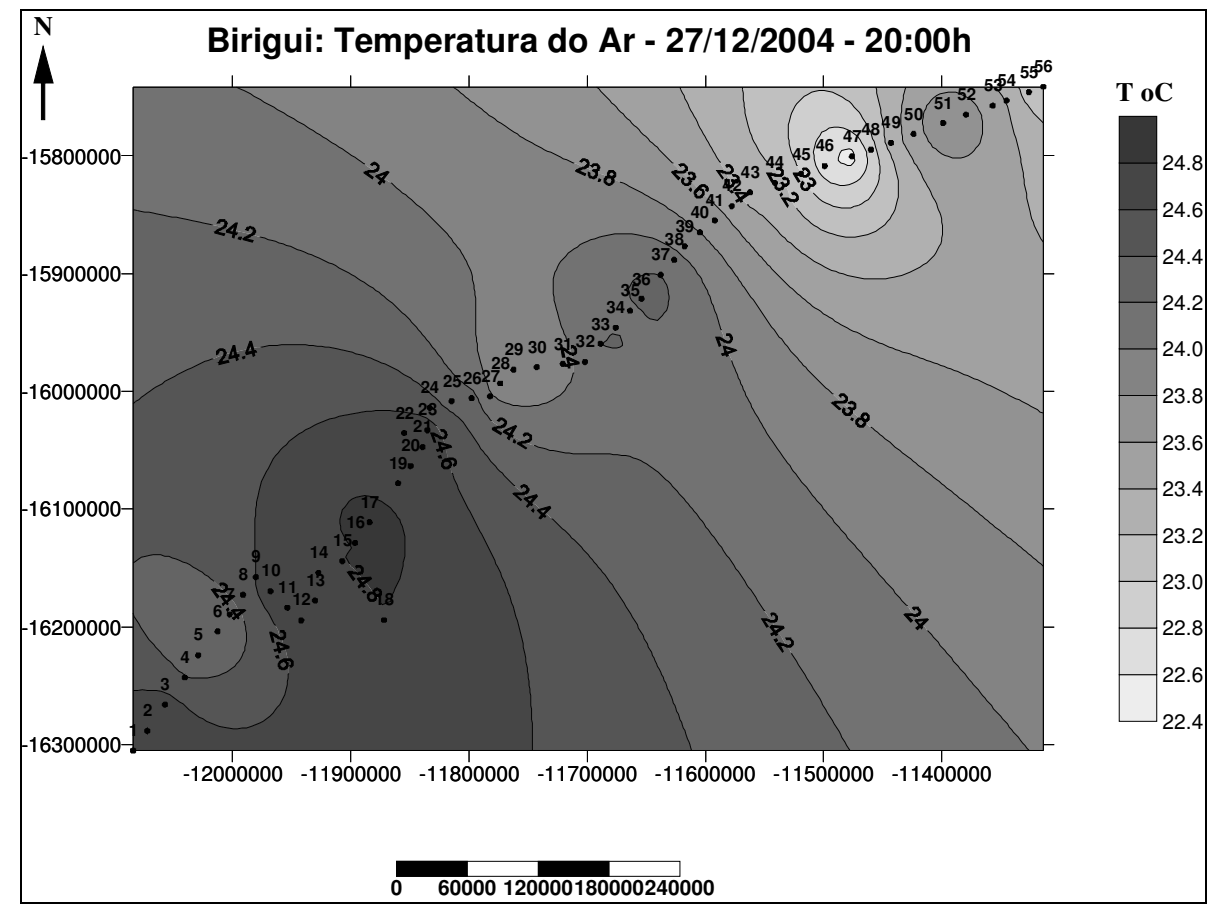

Figura 3. Carta de isotermas: Birigui - 27/12/2004 - 20:00 h.

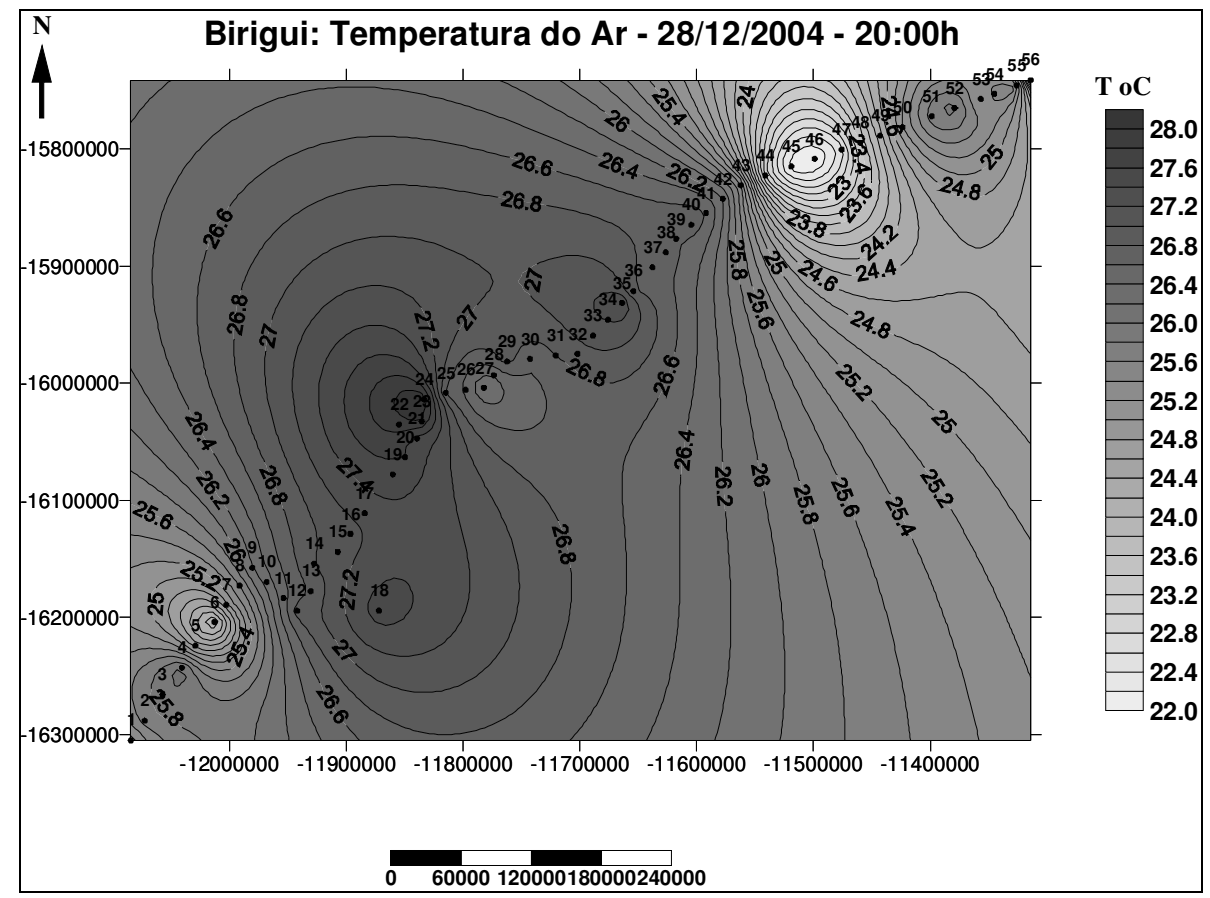

Figura 4. Carta de isotermas: Birigui - 28/12/2004 - 20:00 h.

Nos dias 28/12/2004 a 31/12/2004, com o enfraquecimento da Massa Polar as temperaturas apresentaram-se em elevação, não houve 
precipitação e a velocidade do vento oscilou de 0 a $1,7 \mathrm{~m} / \mathrm{seg}$. A nebulosidade foi fraca mesmo com a atuação de áreas de convergência de umidade (ZCAS) alinhadas com frentes frias que atuaram no litoral da Região Sudeste e Sul neste período.

No dia 28/12/2004, também sob condições favoráveis, a magnitude da ilha de calor foi ainda maior. Sob condições de calmaria e céu limpo, a amplitude térmica entre os pontos foi de $6,2^{\circ} \mathrm{C}$ (Figura 4). Cabe destacar que, embora o vento tenha sido classificado entre 0 e $0,5 \mathrm{~m} / \mathrm{seg}$., segundo a "Escala de Força de Vento de Beaufort", encontrava-se mais fraco do que no dia 24/12/2004.

Nos dias 29, 30 e 31 de dezembro de 2004, as amplitudes térmicas entre os pontos foram respectivamente de $4,7^{\circ} \mathrm{C}, 4,5^{\circ} \mathrm{C}$ e $4,6^{\circ} \mathrm{C}$, sob condições de calmaria e baixa nebulosidade. (Figuras 5, 6 e 7).

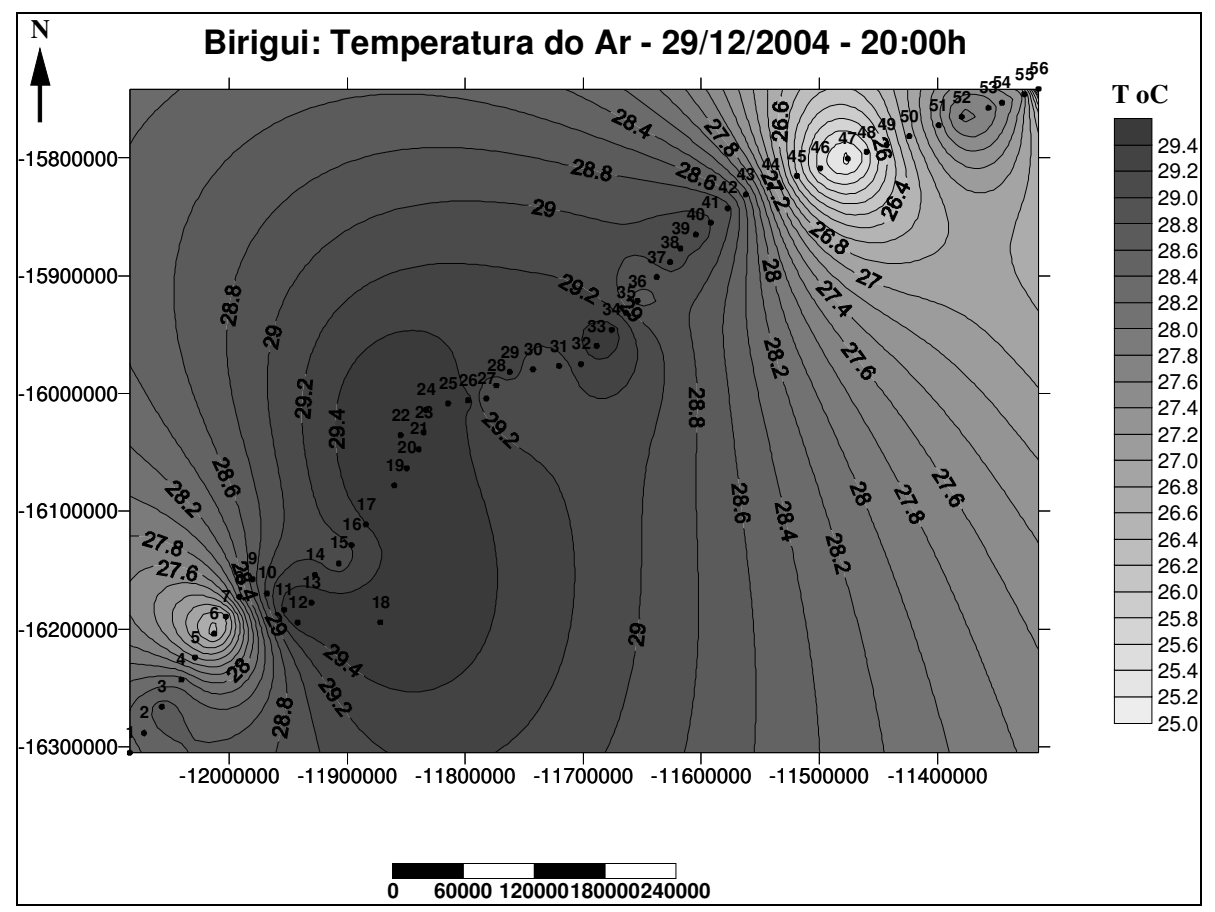

Figura 5. Carta de isotermas: Birigui - 29/12/2004 - 20:00 h.

No dia 01/01/2005 registrou-se queda na amplitude térmica para $2,7^{\circ} \mathrm{C}$ devido à atuação das áreas de instabilidade que provocaram mudanças no comportamento do tempo e conseqüentemente, aumento na velocidade do vento (entre 5,3 e 7,4m/s) e elevação da nebulosidade para 70\%. (Figura 8)

Os parâmetros meteorológicos que afetaram de maneira mais clara a intensidade da ilha de calor foram a velocidade do vento e a nebulosidade.

A relação entre o tamanho da cidade e a velocidade do vento necessária para fazer desaparecer a ilha de calor foi demonstrada por Oke e Hannell (1970), em estudo realizado em Hamilton (Canadá), sendo, portanto a velocidade do vento um parâmetro meteorológico importante para se considerar em estudos desta natureza. 


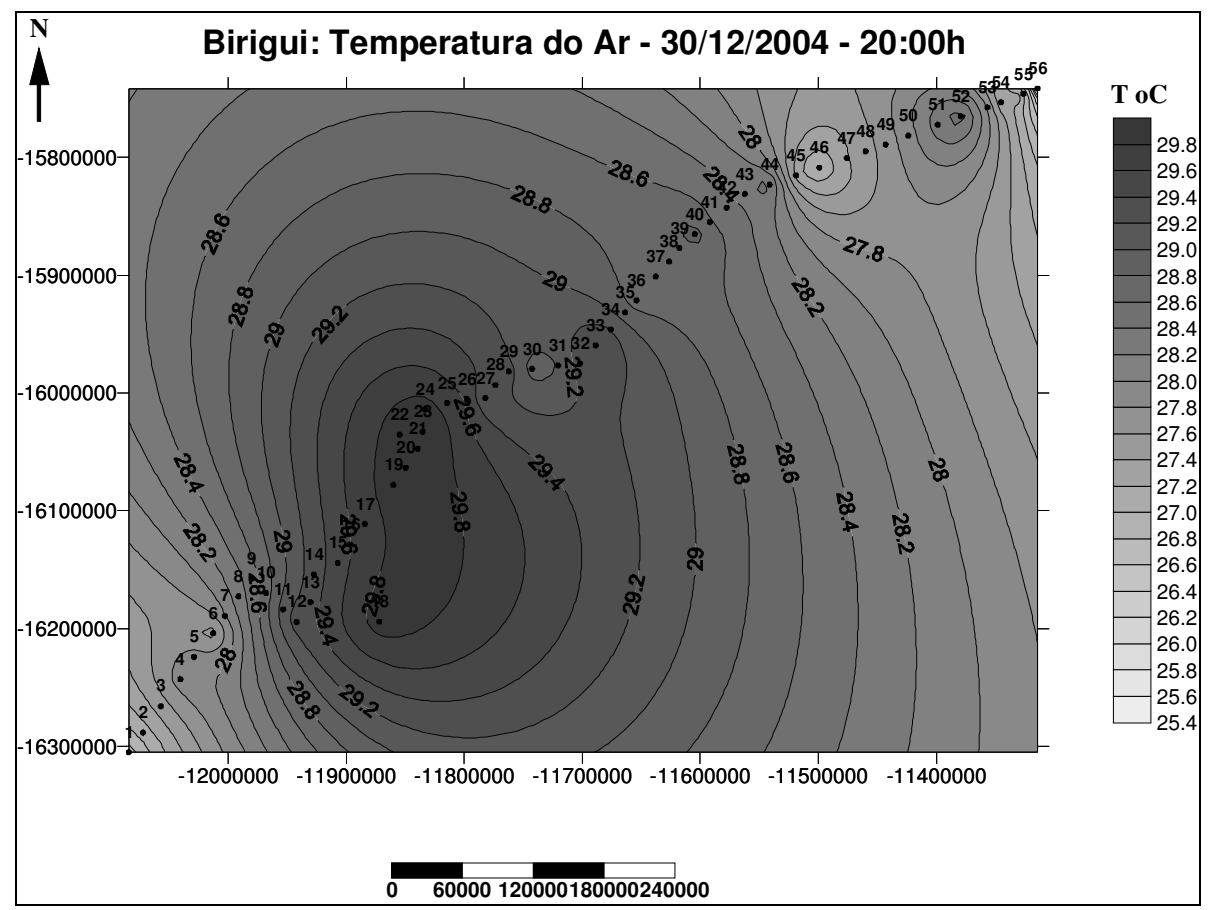

Figura 6. Carta de isotermas: Birigui - 30/12/2004 - 20:00 h.

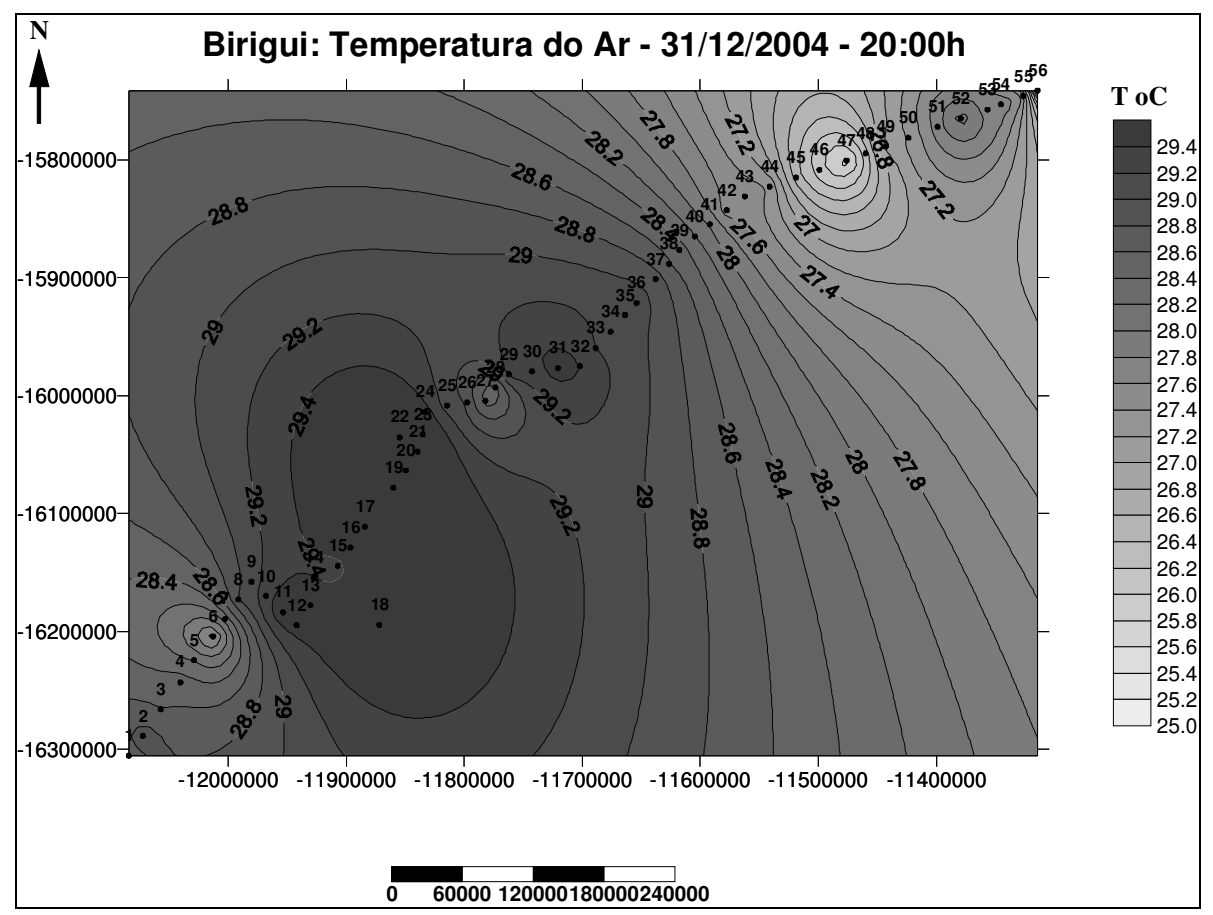

Figura 7. Carta de isotermas: Birigui - 31/12/2004 - 20:00 h.

No que diz respeito à distribuição espacial da temperatura verificouse que a grande diferença entre os pontos de coleta esteve relacionada com a densidade de construções. As maiores temperaturas foram observadas nas 
áreas centrais e nos bairros densamente construídos.

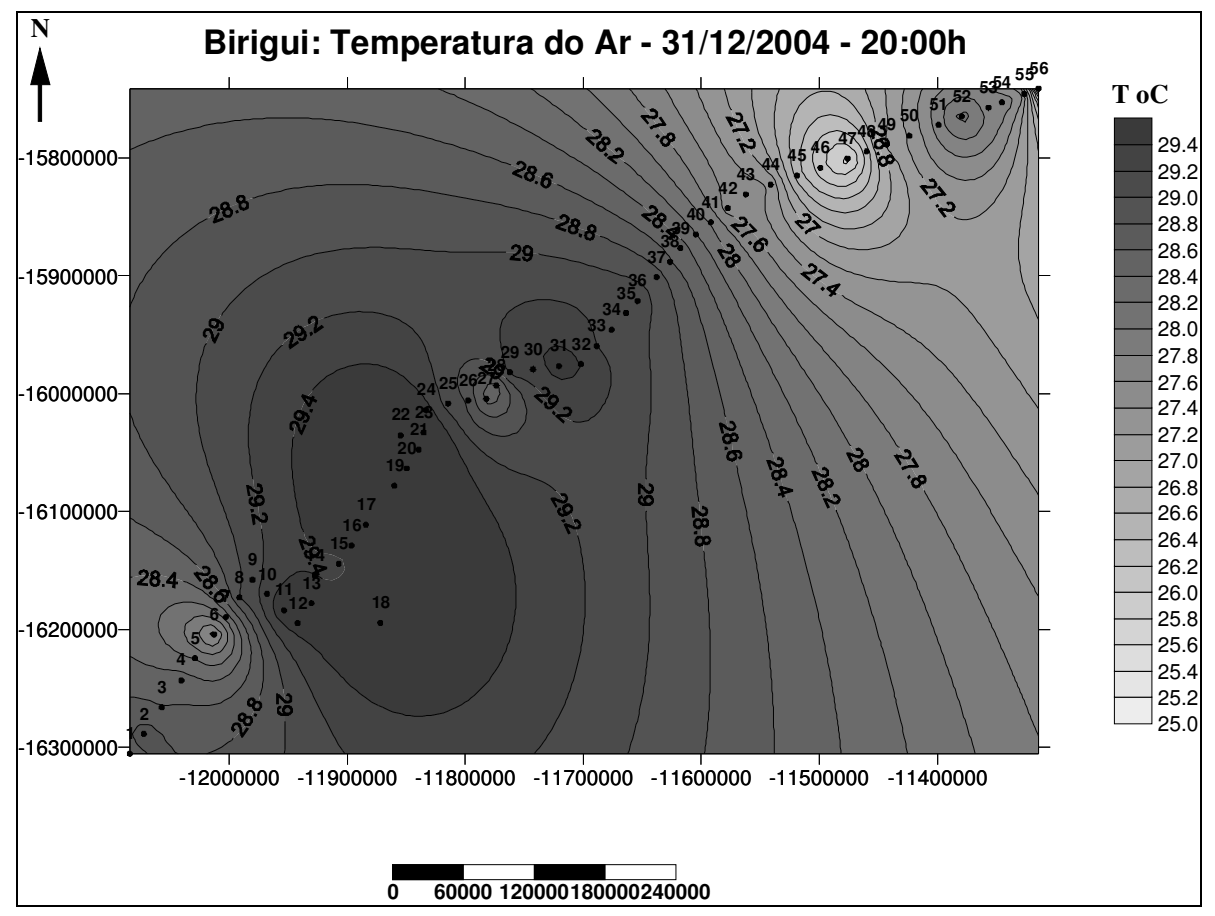

Figura 8. Carta de isotermas: Birigui - 01/01/2005 - 20:00 h.

Em Birigui notou-se que sob condições sinóticas favoráveis um grande bolsão de ar quente se formou sobre a área mais densamente construída. As ilhas frias foram verificadas no ambiente rural, tanto no início do percurso, entre os pontos 1 e 8, como no final do percurso a partir do ponto 42 . Observou-se uma queda significativa da temperatura nas chácaras localizadas na porção nordeste, que ficam entre residenciais relativamente recentes da cidade. Nos residenciais as temperaturas tiveram um pequeno aumento $e$ voltaram a diminuir no meio rural a partir do ponto 53.

No dia 25/12/2004 (Figura 2), se verificou em Birigui a importância da direção do vento na diminuição da área de abrangência da ilha de calor e por outro lado, a expansão da ilha de frescor. Sob a atuação de ventos do quadrante leste, com velocidade estimada entre 3,4 - 5,2m/seg., as temperaturas mais baixas decorrentes de chácaras e do meio rural, foram levadas para a área densamente construída, deixando a ilha de calor, de média magnitude, restrita ao "core" urbano. Situação parecida ocorreu no dia 27/12/2004. (Figura 3)

\section{Considerações finais}

Os dados coletados nesta pesquisa evidenciaram que Birigui apresenta um perfil térmico que coincide com grande parte dos estudos realizados no período noturno, os quais registram na área mais densamente construída, um pico positivo de temperatura.

As isotermas apresentaram uma disposição concêntrica em torno 
das áreas densamente construídas, assinalando as áreas de temperaturas mais elevadas, configurando as ilhas de calor.

Há várias causas que originam as ilhas de calor e dentre elas destacam-se: o armazenamento de calor durante o dia na cidade, graças às propriedades térmicas e caloríficas dos materiais de construções e sua devolução para a atmosfera durante a noite; a produção do calor antropogênico (circulação de veículos e pessoas); a diminuição da evaporação decorrente da substituição da superfície original por concreto e asfalto e a canalização fechada de rios e córregos e a menor perda de calor sensível, devido à redução da velocidade do vento originada pelas edificações.

Deve-se ressaltar que este estudo torna-se relevante na medida em que Birigui não possui Estação Meteorológica para diagnosticar eventuais mudanças no clima devido ao seu processo de crescimento. Entretanto, sob condições atmosféricas ideais, a cidade apresenta microclimas que precisam ser considerados pelos planejadores para que sejam tomadas medidas que contribuam com a melhoria da qualidade ambiental e de vida da população. As ilhas de calor criam uma circulação do ar na cidade que favorece a concentração de poluentes, podendo provocar distúrbios nas pessoas, tais como: doenças respiratórias, circulatórias, e, nos países tropicais, grande desconforto térmico, provocado pelas altas temperaturas comuns nestas latitudes.

\section{Referências bibliográficas}

AMORIM, M. C. C. T. O clima urbano de Presidente Prudente/SP. São Paulo, 2000. 374p. Tese (Doutorado em Geografia) - Faculdade de Filosofia, Letras e Ciências Humanas, Universidade de São Paulo.

CASTILHO, Eduardo. Análise da temperatura e umidade relativa do ar na área urbano - rural de Birigui - SP. Presidente Prudente: FCT/UNESP, 2005. (Relatório FAPESP).

GARCÍA, FERNÁNDEZ F. Manual de climatología aplicada: clima, medio ambiente y planificación. Madrid: Editorial síntesis, S.A., 1996. 285p.

GOMEZ, A. L., GARCIA, F. F. La isla de calor en Madrid: avance de un estudio de clima urbano. Estudios Geográficos, 45, n.174, p.5-34, enero-marzo 1984.

JOHNSON, D. B. Urban modification of diurnal temperature cycles in Birmingham, U. K. Journal of climatology. v. 5, p. 221-225, 1985.

MONTEIRO C. A. de F. Teoria e Clima Urbano. São Paulo: IGEOG/USP, 1976. 181p. (Série Teses e Monografias, 25).

OKE, T. R.; HANNELL, F. G. The form of the urban heat island in Hamilton, Canada. Urban climatology. Tech. Note 108, p. 113-126, Genebra, W.M.O., 1970.

OKE, T. R., MAXWELL, G.B. Urban heat island dynamics en Montreal and Vancouver. Atmospheric Environment, v.9, p.191-200, 1975.

PITTON, S. E. C. As cidades como indicadores de alterações térmicas. São Paulo, 1997. 272p. Tese (Doutorado em Geografia Física) - Faculdade de Filosofia, Letras e Ciências Humanas, Universidade de São Paulo. 